\title{
Construction of Nafion/Hb/Au/ZIF-8/CILE and its application as electrochemical sensor for determination of bromate and nitrite
}

\author{
Juan Liu ${ }^{1,2}$, Wenju Weng ${ }^{2}$, Chunxiao Yin ${ }^{2}$, Guiling Luo ${ }^{1}$, Hui Xie ${ }^{1}$, Yanyan Niu ${ }^{1}$, Xiaoyan Li ${ }^{1}$, \\ Guangjiu $\mathrm{Li}^{2}$,Yaru Xi ${ }^{1}$, Yutong Gong ${ }^{1}$, Shuyao Zhang ${ }^{1}$, Wei Sun ${ }^{1 *}$ \\ ${ }^{1}$ Key Laboratory of Tropical Medicinal Plant Chemistry of Ministry of Education, College of \\ Chemistry and Chemical Engineering, Hainan Normal University, Haikou 571158, China; \\ ${ }^{2}$ Key Laboratory of Optic-electric Sensing and Analytical Chemistry for Life Science of Ministry of \\ Education, College of Chemistry and Molecular Engineering, Qingdao University of Science and \\ Technology, Qingdao 266042, China; \\ *E-mail: sunwei@hainnu.edu.cn
}

doi: $10.20964 / 2019.02 .16$

Received: 10 October 2018/ Accepted: 17 November 2018 / Published: 5 January 2019

In this paper zinc-based metal organic framework material (ZIF-8) modified carbon ionic liquid electrode (CILE) was prepared and electrodeposited with gold nanoparticles to get a composite modified electrode, which was used as the sensing interface for the immobilization of hemoglobin $(\mathrm{Hb})$ with Nafion to prepare a modified electrode (Nafion/Hb/Au/ZIF-8/CILE). Electrochemical behaviors of $\mathrm{Hb}$ on the modified electrode were checked by cyclic voltammetry with a pair of well-defined redox peaks appeared. The effects of $\mathrm{pH}$ and scan rate on direct electrochemistry of $\mathrm{Hb}$ were studied with electrochemical parameters calculated. The prepared electrochemical enzyme sensor showed good catalytic activity to the electroreduction of bromate and nitrite with the linear ranges from 0.5 to 10.0 $\mathrm{mmol} / \mathrm{L}$ and from 0.1 to $0.8 \mathrm{mmol} / \mathrm{L}$, respectively. The detection limits were calculated as $0.83 \mathrm{mmol} / \mathrm{L}$ and $0.03 \mathrm{mmol} / \mathrm{L}$, and the water samples were analyzed to prove the practical application.

Keywords: carbon ionic liquid electrode, zinc-based metal organic framework, gold nanoparticle, hemoglobin, electrochemistry, bromate

\section{$\underline{\text { FULL TEXT }}$}

(C) 2019 The Authors. Published by ESG (www.electrochemsci.org). This article is an open access article distributed under the terms and conditions of the Creative Commons Attribution license (http://creativecommons.org/licenses/by/4.0/). 